\title{
Inovando métodos na educação continuada dos engenheiros de produção*
}

\section{Guilherme Ary Plonski}

Prof. assistente doutor do Departamento de Engenharia de Produção da EPUSP \& Departamento de Administração da FEAUSP - Rua Tiapira 22 CEP 05578 São Paulo (SP) Tel: (011) 813-6953 Fax (011) 814-7496 - Correio cletrônico: - PLONSK12a tBRUSI'VM.BITNET

Palavras-chave: Modernização empresarial, implantaçãode sistemas informatizados, treinamento empresarial

Key words: Industrial modernization, computer sytems implementation, industrial training

\section{RESUMO:}

O presente trabalho discute o papel dos engenheiros de produção no processo de assimilação das novas tecnologias bascadas na informática pelas organizações produtivas.

Conclui-se pela necessidade de sensibilizar esses profissionais, quer no scu estágio de formação como, especialmente, no de educação continuada após a conclusão do curso.

Identificam-se os métodos educacionais disponíveis, focalizando com detalhe aquele bascado em experiências estruturadas.

É apresentado um caso prático bem sucedido, c discutido o potencial para utilização em outras tecnologias de Informática de interesse para o engenheiro de produção.

\section{ABSTRACT:}

This paper is concerned with the production engineer role of activities when implement ing computer based technologies in the production environment. The ed ucation methods based on the structured approach are presented and a practical case study is described, pointing out the potencial applications in the current activities of production engineers.

The conclusions arrive to the needs of ind ucing production engineers on permanent education after graduate course conclusion.

${ }^{*}$ Este trabalho, que se baseia em Seminário Interno realizado no Departamento de Engenharia de Produção da Escola Politécnica da Universidade de São Paulo, em 3 de maio de 1989, foi a presentado no 9o. ENEGEP - Encontro Nacional de Engenharia de Produção. 


\section{Introdução}

Um problema que afeta a maior partedas organizações é a inadequada assimilação de novas tecnologias bascadas na Informática. Volumes expressivos de recursos sãogastos em computadores, e outros dispositivos com retorno geralmente bastante aquém do esperado pela direção das cmpresas.

Um dos fatores que contribui para isso é a condução incorreta da preparação da organização para funcionamento no ambiente informatizado. $O$ erro ć tanto de conteúdo como de processo. Em termos de conteúdo, focaliza-se, em todos os níveis, o detalhe da tecnologia, ao invés dedebatero potencial de utilização gerencial dos novos recursos. Em termos de processo, aplicam-se metodologias de treinamento voltadas ao adestramento no uso de equipamentos, ao invés de métodos que facilitem o processo de a prendizagem do potencial que a tecnologia pode oferecer.

Os engenheiros de produção podem assumir papel relevantecomoarticuladorescapazes de viabilizar organizacionalmente as novas tecnologias. Para isso, eles devem ser sensibilizados para o uso gerencial das tecnologias bascadas na Informática.

Opresente trabalhoidentifica os métodos cducacionais disponíveis e focaliza com detalhe aquele baseado $\mathrm{cm}$ experiências estruturadas. Fundamenta-scele num processode cinco fases, envolvendo:

(1) vivência de uma situação concreta,

(2) compartilhamento da vivência,

(3) processamento da vivência,

(4) generalizaçãodos conceitosenvolvidos na vivência, e
(5) aplicação dos conceitos a situações novas.

\section{Educação para o \\ uso gerencial da informática}

É muito complexo o processo de introdução de uma tecnologia poderosa, como a da Informática, numa organização, de modo a que esta passe a utilizar o seu potencial para aperfeiçoamento gerencial e para diferenciação estratégica.

Assim, para que a inovação tecnológica scja eficaz, o processo educativo deve levar em conta três niveis: transformações geradas no trabalho individual, nas áreas funcionais e na organização como um todo (Gibson e Jackson, 1987).

A questão básica nãoé, pois, comotreinar os engenheiros de produção-que, conforme mostra a experiência (ao menos noestado de São Paulo), rapidamente assumem a função de administradores de nível gerencial e exccutivo nas organizações - a operar a tecnologia. Operar a tecnologia scria, por exemplo, como programar microcomputadores, ou como trabalhar com um particular "pacote" aplicativo. $\mathrm{O}$ verdadeiro desafio é como fazerosadministradoresaprenderem a utilizar a tecnologia.

O autor acredita que pessoas $\mathrm{cm}$ geral, particularmente os engenheiros de produção, podem ser treinadas ou ensinadas a sc tornarem mais produtivas ou eficientes. Em contrapartida, os administradores - quer da produção comode outras árcas funcionais - não podem ser treinados a serem eficazes, ou para transformarem o seu trabalho, a área em que atuam ou a organização para a qual trabalham. Eficácia c transformação devem 
ser aprendidos pelos engenheiros de produção que assumem funções gerenciais ou executivas.

Esse paradoxo é explicado pelo fato de que oambiente das atividades de gestão (nos niveis tático e estratégico) contém um nível elevado de incerteza e a mbigüidade. É muitodificil ensinar uma pessoa a lidar com incerteza e ambigüidade; a pessoa pode, isto sim, aprender a tratar comesseselementos, principalmentea partir da sua própria experiência concreta. Desta forma, o papel do educador envol vido na educação continuada dos engenheiros de produção volta-se mais à facilitação do processo de aprendizagem do que ao treinamento ou ensino convencionais.

\section{Abordagens metodológicas}

Diversas abordagens metodológicas são utilizadas na educação gerencial e são aplicáveis à educação continuada dos engenhciros de produção. A Figura 1 mostra ocontinuum de opções, segundo o grau de envolvimentoque permitem (Pfeiffer, 1985).
Do lado esquerdo há alguns métodos mais tradicionais, focalizados no ensino, em que o professor é o centro do processo. Do lado direito há alguns métodos mais orientados para a vivência, focalizados na aprendizagem, com o estudante no centro do processo.

Todas as abordagens podem ser utilizadase deverãoser selecionadas de acordocom o propósito e as condições de cada particular evento educacional. Parafraseando o enunciado da Teoria da Contingência, não existe uma única abordagem metodológica melhor para a educação gerencial; contudo, nem todos os métodos serão igualmente eficazes numa dada situação. Por isso, a questão é selecionar a melhor abordagem para cada situação.

Uma contribuiçãodeste trabalhoéa apresentação da abordagem do "método combinado", que procura mesclar diversas abordagens disponíveis, bascadas numa experiência estruturada. Assim, por exemplo, cada evento no programa de Educação para a Utilização Gerencial da Informática, a que se faz referência adiante, tem a sua própria metodologia.

\begin{tabular}{l} 
baixo \\
\hline \hline $\begin{array}{l}\text { Espectador } \\
\text { Passivo }\end{array}$ \\
\hline L \\
\hline
\end{tabular}

Figura 1 
A experiência que constitui ocaso focalizado neste trabalho apresenta uma solução para o importante tema da avaliação de um sistema de informação, preocupação relevante tanto dos profissionais envolvidos na administração de uma empresa comodaqueles que desenvolvem sistemas. É uma combinação dos métodos do caso, "role playng" e simulação, todos urdidos no tecido de uma experiência estruturada.

\section{A abordagem vivencial}

Asexperiênciasestruturadas estãobaseadas na abordagem vivencial. Um dos primeiros modelos utilizados nessa administração é o processo de aprendizagem, desenvolvido a partir de uma perspectiva psicológica (Kolb, 1974). O modelo foi aperfeiçoado e agora é concebido, conforme retratado na Figura 2, como sendo um processo cíclico de cinco estágios (Pfeiffer, 1985):
(1) Vivência de uma situação concreta, que permiteao participantercunir dados para o seu processo de aprendizagem; nesse estágio é essencial uma atividade prática, do tipo "hands-on";

(2) Compartilhamento da vivência com os outros participantes e reflexão sobre as reações de cada um;

(3) Processamento da vivência, buscando encontrar sua dinâmica e característica relevantes;

(4) Generalização dos conceitos envolvidos na vivência, indeferindo os principios vigentes no "mundo real" c formando os conceitos abstratos; $\mathrm{e}$

(5) Aplicação dos conceitos a situações novas (co planejamentodecomo fazê-lo), oque significa a incorporação e o teste daquilo que foi aprendido.

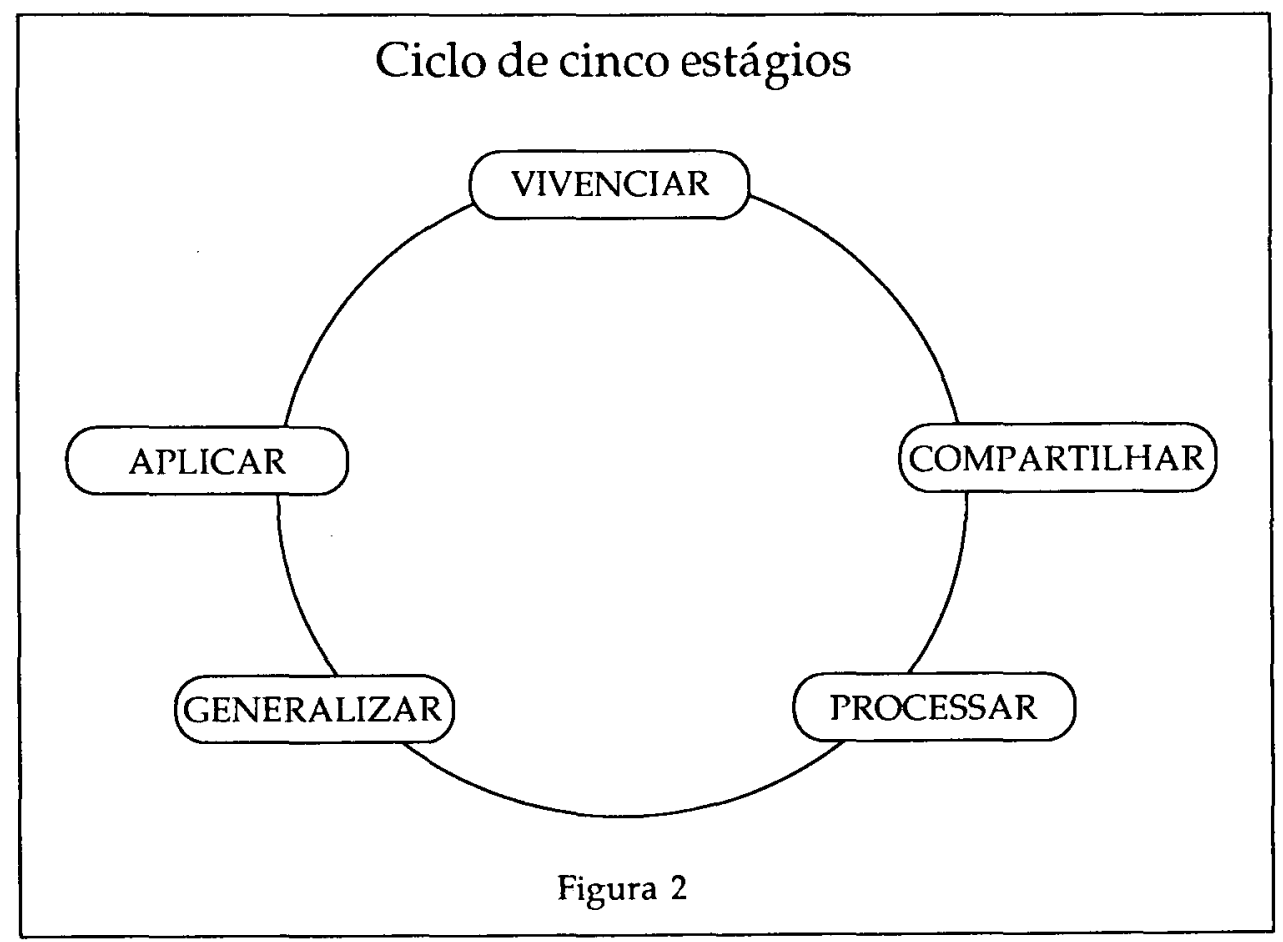


Este modeloopera com base emexperiências estruturadas, que permitem aos participantes aprender indutivamente e energizar todo o ciclo.

\section{O caso: avaliação de um sistema de apoio à decisão}

Este tópico apresenta uma aplicaçãobem sucedida da metodologia proposta para facilitar a aceitação de novas tecnologias pelas organizações.

O caso focalizado visou a promover uma percepção cocrente do valor de sistemas de apoio à decisão por parte dos usuários e dos opcradores da tecnologia de Informática. Elc integra um programa de Educação para a Utilização Gerencial da Informática(EDIN), que vem sendo realizadoem diversas empresas brasilciras destacadas.

\section{AVALIAÇÃO DE UM SISTEMA DE APOIO À DECISÃO}

Sistemas de Apoio à Decisão (SAD) são projetados com o fim precípuo de tornar os computadores úteis aos administradores. Ocorre que estes, geralmente, tiraram pouco ou nenhum proveito da "revolução dos computadores", ainda que cles possam ter sidobenéficos aos supervisores de atividades rotinciras e, por vezes, também à empresa como um todo.

A fim de que possam contribuir para aumentar a eficácia dos administradores, os computadores devem apoiar - $\mathrm{c}$ não substituir-aqueles que tomam decisões. Nas palavras de um especialista, "um SAD é, cm verdade, um assistente ao qual oadministrador delega atividades envolvendobusca, manipulação e relato" (Keen, 1981).
Surgem algumas questões básicas:

- como projetarSADs feitos sob medida, uma vez que cada administrador tem o seu próprio estilo de tomada de decisão?

- comofazer com queos profissionaic responsáveis por desenvolvimento de sistemas, treinados para serem altamente analíticos e avessos à ambiguidade, compreendam a racionalização própria dos administradores, que devem decidir em condições de pressão de prazo c de incerteza?

- comoestimular pessoas com experiência relativamente incipiente em computação c métodos analíticos a interagir com um SAD?

Estas questões são focalizadas pelo autor (junto com ou tros colegas) no citado EDIN. A solução consubstancia-se numa experiência estruturada para avaliação deSADs, com duração de quatro horas, denominada "O valor de sistemas de informação". Essa experiência combina diversos métodos didáticos passíveis de serem utilizados para facilitação do processo de aprendizagem, mencionados em tópico anterior.

\section{A EXPERIÊNCIA}

Apresenta-se, a seguir, um esboço da experiência estruturada utilizada. Osconceitos subjacentes já foram expostos e os resultados são discutidos adiante.

\section{Objetivo e Participantes}

Oexercício permite aos participantes vivenciar a concepção e o desenvolvimento de umSAD. Assim, cles participarãodo processo de avaliaçãode um sistema de informação, em termos do seu valor para o usuárioe para a organização como um todo. Poderão, também, discutir as vantagens relativas dos distintos métodos de avaliação de um sistema de informação. 
Ogrupo ideal tem cerca de vinte participantes, entre ad ministradores de nívelexecutivoe/ou gerencial (incluindo, em proporção maior ou menor, engenheiros de produção) e pessoal da área de Informática ou Sistemas (usualmente incluindo também engen heiros de produção) de nível comparável.

Os participantes são divididos em cinco equipes de mesmo tamanho, devendo cada equipe incluir tanto administradores como pessoal de sistemas. Quatro dessas equipes assumirão o papel de desenvolvedores de sistemas, enquanto a quinta assumirá a posição da diretoria de uma empresa, instada a tomar uma decisão importante para a estratégia de seu negócio.

No início do exercício cada participante recebe a seguinte informação escrita:

- os objetivos da experiência estruturada

- um texto introdu tório conciso sobre Análise de Valor e sobre SAD, e

- a descrição dos passos seguintes do exercício.

\section{Informações e Recursos Fornecidos}

Cada uma das quatro equipes que atuam no papel de desenvolvedores de sistemas recebe, adicionalmente, um memorando da diretoria (preparado antes pelos facilitadores), apresentando um caso resumido e pedindoum protótipode $S A D$, a serentregue num prazo determinado, a fim de ajudá-la a melhorar a decisão estratégica que está em vias de tomar.

Um exemplo de tal decisão para uma indústria poderia ser o número e a localização de novas unidades de armazenamentoe distribuição de materiais (matérias primas e produtos acabados), a fim de que seja melho- rada a qualidade do atendimento ao mercado, de modoa alcançar um desempenhooperacional e econômico-financeiro previsto para operíodode planejamento subscquente. $\mathrm{O}$ memorando inclui alguns fatores que a diretoria gostaria de ponderar antes de decidir.

Essas equipes recebem os seguintes recursos para desenvolver oSAD:

a) Um microcomputador carregadocom programasaplicativos básicos (planilha, banco de dados, gerador de gráficos, processador de texto, etc.);

b) Uma base de dados acerca de temas relevantes para a decisão;

c) Uma cópia de documentosobre programas aplicativos básicos para informação gerencial, que provê de forma concisa explicações acerca do conteúdo c utilidade dos programas disponíveis já enunciados; $\mathrm{e}$

d) Um operador de microcomputador experiente ("piloto de micro").

Enquanto isso, a equipe que faz o papel de "diretoria" recebe uma folha de instruções explicando as tarefas que a "diretoria" deve realizar durante a preparação e a apresentação do SAD. A folha também chama a atenção para algumas caracatcrísticas importantes de um SAD.

Adicionalmente, a "diretoria" recebe cópia do memorando entregue às equipes de desenvolvimento de sistemas, assim como dos dados contidos na base acessivel às equipes de desenvolvimento de sistemas.

Um consultor familiarizadocomoassunto objeto da discussão é postoà disposiçãoda "diretoria". 


\section{O Desenvolvimento da Experiência}

Após lera informaçãoinicial (20minutos), os participantes são divididos em equipes $e$ se encaminham para os locais apropriados, onde encontram as informações e os recursos descritos.

Asquatroequipesdedesenvolvimentode sistemas têm 90 minutos para desenvolvero protótipodeSAD que scrá submetidoà "diretoria"; esta, obviamente, selecionará apenas uma das propostas.

Enquanto isso, os integrantes da "diretoria" discutem critérios para avaliar as propostas de SAD que surgirão. Eles podem envolver o consultor na discussão por um máximo de 30 minutos, a fim de obter orientação especializada. A "diretoria" deve, outrossim, esclarecerqualquer questãosobre os requisitos doSAD que lhe venha a ser posta pelos desenvolvedores de sistemas.

Decorrido o tempo de preparação, cada um dos quatrogrupos apresenta sua proposta de SAD (tempo disponível por equipe: 15 minutos +5 minutos para a elucidação de questões a presentadas pela "diretoria"). Todos os grupos assistem a todas as exposiçōes.

Em seguida, a "diretoria" avalia as propostas em sessão "pública" e decide qual a que, em sua opinião, tem maior valor (20 minutos).

Finalmente, ofacilitador organiza e coordena uma discussão acerca dos tópicos suscitados pela experiência. Inicialmente cle pede relatos acerca do que ocorreu durante a preparação do SAD no seiode cada equipe de desenvol vimento de sistemas, bem como na "diretoria". Em seguida, o facilitador insta os participantes a fazer em comentários, levanta questões e, também, envolve o consultor no debate. A discussão, que gradualmente evolui da experiência compartilhada para situaçōessimilares na organização, deve durar cerca de 60 minutos.

Alguns tópicos para debate podem ser:

- como a equipe se organizou?

- qual foi o papel e a utilidade do "piloto de micro"?

- como foram definidososcritérios da "diretoria"?

- que fatores explícitos $\mathrm{e}$ latentes afetaram a decisão da "diretoria", como scja a qualidade da apresentação?

- qual foi a influência docronograma apertado?

- o caráter evolutivo de um SAD foi considerado?

- como foram contemplados os fatores associados a custo?

- a "amigabilidade" do SAD foi cxaminada?

O facilitador faz as obscrvações finais accrca do valor de um sistema de informação e ressalta os momentos marcantes da experiência recém completada.

\section{RESULTADOS}

\section{Aspectos Comportamentais}

A aplicação prática do exercício descrito apresentou resultados excelentes em termos educacionais. Isso se deve, em primeiro lugar, ao fatode despertar nos participantesum nível elevado de interesse por um prazo longo. Isso não seria possível com uma palestra convencional sobre o valor de sistemas de informação. 
Mas os resultados mais excitantes decorrem daspercepções intuitivas ("insights" -ou, na linguagem popular, "sacações") que a experiência permite. Por exemplo, as equipes de desenvolvimento de sistemas geralmente usam a totalidade dos 90 minutos trabalhando denodadamente na preparação do protótipo do SAD, sem qualquer contato, ao longo desse período, com a "diretoria" que solicitou oapoio. Mesmoquandosurgemdúvidas de interpretação acerca dos termos do memorando recebido, aqueles que desenvolvem os sistemas geralmente preferem resolvê-las segundo scus próprios critérios a pedir esclarecimentos à "diretoria". Ficam, então, surpresos, ao constatar que os demais grupos podem ter tido um entendimento diverso a respeito de algunsdos critérios sugeridos e que a sua interpretação não correspondia à idéia que perpassava as mentes dos "diretores".

Esse fato ocorria, ironicamente, apesarde estarem tanto os desenvolvedores de sistemas quantoos "diretores" instalados na mesma sala (ou, no máximo,em salas contíguas) durante a experiência, sem qualquer impedimento à comunicação.

Em verdade, isso expressa um padrãode comportamento bastante similar ao que ocorre no "mundo real" com as equipes de desenvolvimento de sistemas. E esse comportamento se manifesta durante a experiência a pesar dea maioria dos integrantes dessas equipes ser constituida de administradores, acostumados a criticar essa postura dos analistas de sistemas da sua organização.

Essa percepção muito importante pode bem ser resumida na declaração de um participante, gerente em sua empresa, que havia se sensibilizado por esse seu comportamento durante oexcrcício: "Acabode medar conta de que eu estava trabalhando para um memorando e não para diretores de carne e osso".

\section{Resultados Substantivos}

A experiência também permite a discussão dos tópicos mais importantes relativos à avaliação de um SAD, tais como:

a) A existência de SADs com estruturas diversas, que aparecem nas propostas apresentadas pelas equipes de desenvolvimento de sistemas, tais como: modelos baseados em dados; modelos enfatizando o uso de gráficos; algoritmos de decisão parametrizados; modelos que apresentam uma única proposta de solução, e assim por diante;

b) As limitações dos métodos tradicionais de análise de custo-benefício para incorporar a natureza dos benefícios percebidos num tal sistema de informação: o valor deve prevalecer sobre ocusto, uma vez que a decisão de desenvolver o SAD é concebida mais como um investimento para aumentar a eficácia futura do que como algo que repercutirá imediatamente sobre o resultado econômico da empresa;

c) Oconceitode sistema cvolutivo, subjacente à natureza do desenvolvimento do SAD: ao contráriodos procedimentos analíticos tradicionais, a meta inicial ć um protótipo rápido de ser produzido. A idéia é fornecer aos decisores uma ferramenta útil, ainda que incompleta, mas tempestiva em termos da decisão real quedeveserfeita. Novosaperfeiçoamentos podem depois ser incorporados ao sistema, de conformidade com a experiência, a aprendizagem e as necessidades percebidas do usuário;

d) Os requisitos de simplicidade e robustez de um SAD: os decisores não podem, nem devem, fazer estimativas precisas a respeito de variáveis incertas; $e$

e) A finalidade principal de um SAD, queéa redução da incerteza e do risco. 


\section{Conclusões}

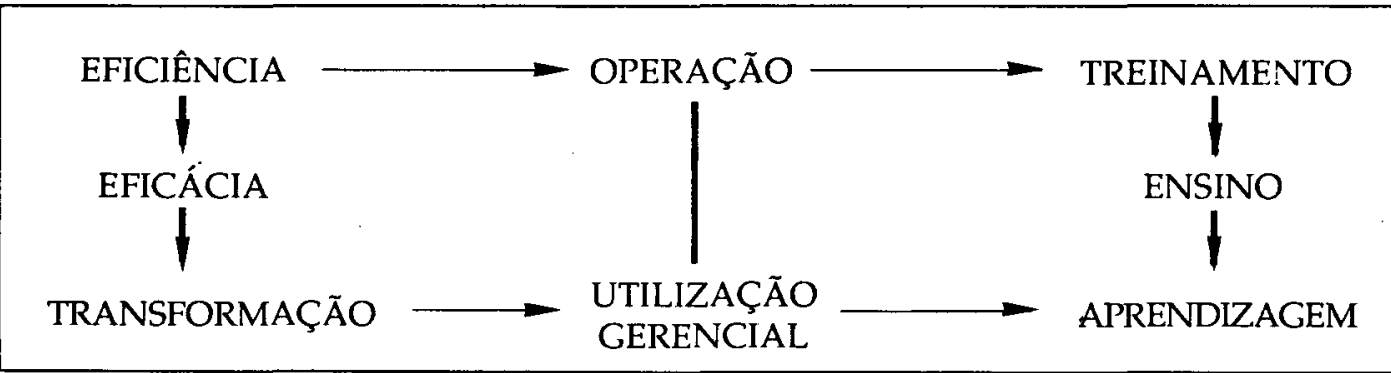

Figura 3 - Evolução Informática X Processo Educacional

A Figura 3 apresenta uma visão global do relacionamento entre uma tecnologia, que no casoé a de Informática, e o processocducativo.

A prática atual de educação continuada de engenheiros de produção que assumem funções gerenciais ou executivas na utilização da Informática deve ser redimensionada em termos do equilíbrio entre os aspectos técnicos e gerenciais. Para incrementar estes últimos, é necessário envolver os participantes numa atmosfera estimulante e agradável.

Colocando as idéias num grado de referência mais amplo, tanto o conteúdo como o processo de qualquer evento educacional devem ser adequadamente planejados. A abordagem do "método combinado", baseada em experiências estruturadas, mostrou bons resultados em seminários realizados em diversas empresas brasilciras destacadas. Ela permite enriquecer as opçōes para facilitar o processo de adoção de ino- vações tecnológicas expressivas, como é o caso da Informática.

Metodologia análoga vem sendo desenvolvida para facilitar a assimilação de CAD pelas empresas (no modelo da ENGEMÁTICA).

\section{Bibliografia}

GIBSON,C.F.\&JACKSON, B.B. Information Imperative. Lexington, 1987.

KEEN, Peter G.W. "Value Analysis: Justifying Decision SupportSystems", in ROCKART, J.F. \& BULLEN, C.V. (cd.) The Rise of Managerial Computing. Dow JonesIrwin, 1986, pp. 69-90

KOLB, David. On Management and the Learning Process in Organization Psychology. Prentice-Hall, 1974. 
PFEIFFER, J. Williams. Reference Guide to Handbooks and Annuals of Structured Experiences. University Associates, 1985.

PLONSKI, G.A. \& SNIFER, M. "A Case Method Approach to Education for Managerial Computing", in KLEIN, Hans E. (ed.) Selected Papers of the Fifth Inter- national Conference on Case Method Research and Case Method Application. Waltham (USA), 23-25 mai. 1988 pp. 299306.

WHISTON, T.G. The Training and Circumstances of the Engineer in the TwentyFirst Century. Sussex (UK), 1987. 